\title{
Intervenções estrangeiras e a presença da América Latina e do Brasil no Haiti ${ }^{1}$
}

Rosny Smarth ${ }^{2}$

No espaço de dez anos, entre 1994 e 2004, o Haiti viveu duas intervenções de tropas estrangeiras em seu território. As duas intervenções foram realizadas sob a égide das resoluções do Conselho de Segurança das Nações Unidas.

A primeira, realizada em setembro de 1994, sob a resolução 940 do Conselho de Segurança, teve como objetivo restaurar a ordem constitucional após o golpe militar do General Cédras, que resultou no exílio do presidente Jean Bertrand Aristide, em finais de 1991. Essa ação implicava no retorno do presidente Aristide, o que se efetivou em outubro de 1994. Como consequência dessa invasão, as Forças Armadas Haitianas ficaram praticamente destroçadas e seu alto comando fugiu para o exílio.

A segunda intervenção foi realizada sob a Resolução 1529, homologada em 29 de fevereiro de 2004, mesmo dia da renúncia e da saída forçada do presidente Aristide do país, e se deu em um ambiente de grandes mobilizações contra o governo e de uma rebelião armada, a cargo basicamente de ex-militares que haviam ocupado praticamente a metade do país. Ocorreu no marco de um governo repressivo, que dirigia ou incentivava grupos paramilitares, além de suborno à polícia e atos criminosos contra seus opositores, a partir do que se falava da existência de um governo delinquente.

A primeira intervenção, ou seja, a de 1994, foi realizada por 20.000 homens sob o comando norte-americano, enquanto a segunda, em número muito menor -

\footnotetext{
1 Palestra proferida no Simpósio Internacional Caminhos de Diálogo para a Construção de uma Diplomacia Responsável: a presença do Brasil no Haiti”, realizado nos dias 27, 28 e 29 de março de 2007, no Centro Universitário de Brasília - UNICEUB. Tradução do espanhol para o português de Renata de Melo Rosa.

2 Ex-primeiro ministro do Haiti.
} 
3.000 - foi realizada, em um primeiro momento, por tropas americanas, francesas e canadenses. Do subcontinente latino-americano, somente as forças chilenas participaram em número reduzido dessa primera etapa, com duração de três meses. Depois, essa força interina seria substituída por soldados de vários outros países, entre os quais, vários latino-americanos, em cuja liderança está o Brasil, o maior país do subcontinente latino-americano e caribenho. A missão dessa segunda intervenção é mais ampla, já que tem por objetivo a estabilização das instituições do país, o que faz com que sua duração seja indefinida. A Missão tem também um componente civil importante cujos propósitos são os de assegurar o respeito aos direitos humanos e buscar ajuda humanitária, se necessário, além de tornar eficiente o sistema judiciário e apoiar o governo nas tarefas de desenvolvimento econômico e social, entre outros. A direção de toda a Missão esteve assegurada por um civil também de origem latino-americana: chileno, ${ }^{3}$ nos dois primeiros anos, e guatemalteco, atualmente. ${ }^{4} \mathrm{O}$ comando militar está nas mãos do Brasil e o número de soldados oscila entre sete e oito mil.

A presença de latino-americanos nessa Missão tem algo de inusitado no continente e certamente se deve a contatos diplomáticos do mais alto nível com os países de forte presença histórica no Haiti, como Estados Unidos e França. É preciso dizer que, pelo fato de se realizar no marco de uma resolução das Nações Unidas, a intervenção se afasta do caráter clássico de uma invasão e do atropelo da soberania nacional, sobretudo porque respondeu a uma demanda oficial do governo interino haitiano, e ao apelo da maioria das forças políticas do país. Poderíamos dizer que responde ao que se tem chamado ultimamente: "a responsabilidade de proteger" ou também "o dever de ingerência", apesar de esses conceitos se prestarem a muita discussão.

Em um primeiro momento, os latino-americanos pareciam descobrir um país totalmente desconhecido para eles. De fato, pouco sabiam do Haiti, senão que era o primeiro país independente do subcontinente com uma linda história

3 O autor se refere a Juan Gabriel Valdez, que exerceu o comando da MINSUTAH de 15 de julho de 2004 a 22 de maio de 2006. Nota da tradutora.

$4 \mathrm{O}$ autor se refere a Edmond Mulet, que foi substituído por M. Hedi Annabi (in memoriam), em outubro de 2007. Nota da tradutora. 
antiescravista, o país com as maiores raízes da raça negra e que agora se encontrava em uma das escalas econômicas mais baixas do mundo. Apesar de conhecerem a miséria e as desigualdades sociais em seus países, a crua realidade haitiana como que os atingiu, e o Haiti foi uma verdadeira descoberta para os latino-americanos, mas uma descoberta com signos mais negativos do que positivos.

Os latino-americanos se emocionaram com o pobre povo haitiano. Não podiam acreditar nessa miséria abjeta a poucos quilômetros dos Estados Unidos e pareciam não aceitar as grandes desigualdades entre o povo e a elite econômica que vivia como "príncipe" em cima das altas colinas frescas de Petion-Ville e Kenskoff. As diferenças soavam como inaceitáveis! Inclusive o mundo intelectual haitiano, com personalidades que falam corretamente, em geral, mais de dois idiomas, e pode dialogar ou discutir com as elites de qualquer país desenvolvido, parecia-lhes demasiadamente sofisticado em um país com mais da metade da população analfabeta. No campo afetivo, os latino-americanos simpatizavam com as comunidades das favelas miseráveis, o povo totalmente despossuído de Porto Príncipe e das grandes cidades como Cabo Haitiano, Jacmel, Cayes, Gonaïves etc. Ao contrário, apesar de terem contato diário com os elementos da burguesia, com dirigentes políticos e com intelectuais, todas essas categorias lhes pareciam muito egocêntricas e com pouca sensibilidade popular. No plano puramente político, os latino-americanos não procuravam entender por que havia tantos partidos ou por que havia tantos intelectuais ou gente de classe média com pretensões políticas tão altas como a de se chegar à Presidência da Républica. Os latino-americanos não se deram conta que, em vários aspectos, o Haiti era a representação extrema de muitas deformações de seus próprios sistemas sociais e políticos e que, por exemplo, o subcontinente latino-americano está classificado como o mais desigual e injusto do mundo e que, portanto, as grandes diferenças sociais e as distâncias entre a elite e as massas não são exclusividade do Haiti.

No entanto, creio também que os amigos latinos não gostavam que a elite haitiana discutisse com eles de igual para igual e criticasse muitas vezes seus pontos de vista. Pelo contrário, os latino-americanos frequentemente mencionavam a altivez do povo pobre que, apesar da miséria mais horrível, não parecia se dobrar e não perdia seu orgulho e dignidade. Mas pareciam não entender que esse orgulho 
era o mesmo que os políticos, intelectuais e as classes médias e altas haitianas carregavam e que a elite haitiana em geral se relaciona com o mundo exterior com plena segurança de si mesma. A verdade é que, para o bem ou para o mal, esse orgulho, que nos vem não sei de onde, talvez do ato heróico da independência, atravessa toda a sociedade haitiana e é, às vezes, um ponto forte de desentendimento ou de discórdia em nossas relações com o exterior que, no mais das vezes, procura se relacionar com atores muito mais dóceis, até submissos. Entretanto, de forma aparentemente contraditória, esse tipo de ator também existe no Haiti, o que dá a esse país um ar de complexidade e de difícil compreensão.

Com essa visão, os latinos pareciam inclinados a tomar posições politicamente favoráveis às massas e contra a elite.

A partir daí, fazia-se uma correlação extremamente direta entre miséria e criminalidade, parecendo justificar a ação dos grupos armados pela miséria em que viviam, e indiretamente pela indiferença das elites. À primeira vista, esse argumento era pelo menos muito parcial, já que os setores mais pobres do país, ou seja, os camponenses, que representam mais de $50 \%$ da população, não manifestam qualquer espírito de violência e de criminalidade. Está claro que a violência dos grupos populares em Porto-Príncipe teve, no início, uma clara conotação política. Tratava-se, pelas armas, de defender Aristide antes de sua queda e. depois, para forçar seu retorno. Provavelmente, com o tempo, a violência se diversificou, adquirindo também aspectos de puro banditismo.

Essa mesma visão levou, a princípio, os latino-americanos a se referirem à necessidade de implantar um novo tipo de cooperação, uma cooperação mais horizontal e que saísse dos cânones clássicos dos organismos internacionais tradicionais e do marco dos grandes países do hemisfério norte. Dizia-se que tantos anos de cooperação com o norte haviam fracassado solenemente e que se deveria buscar outra fórmula.

Em certos círculos haitianos, essas ideias foram interpretadas como a manifestação do afã do Brasil de querer começar a desempenhar um papel de subimpério no subcontinente. A verdade é que, acredito que as coisas não eram bem 
assim, mas, certos comportamentos ou certas críticas prestavam-se a esta interpretação.

A meu ver, essa visão um tanto ideologizada e emocional iria se refletir em certos comportamentos políticos um tanto equivocados, os quais relaciono brevemente a seguir: em primeiro lugar, tal entendimento levou os latino-americanos a superdimensionarem o assunto dos ex-militares que haviam se insurgido contra Aristide, dando-lhes uma força realmente inexistente. Devido a isso, as forças da Minustha e a maioria do corpo diplomático lotado no Haiti concentravam, a princípio, suas preocupações e suas lutas contra esses grupos armados.

Para a maioria dos diplomatas e, especialmente para os latino-americanos, os ex-militares constituíam o principal entrave para o desenvolvimento da democracia no Haiti, já que representavam o poder tradicional que, aliado a outras forças da burguesia, havia levado o país à sua situação atual. Segundo eles, existia sobretudo o perigo que os ex-militares ampliassem sua suposta popularidade e, portanto, pudessem ganhar as disputas eleitorais que definiriam a institucionalidade democrática futura. Sem entrar em muitos detalhes, pode-se dizer que os eventos políticos posteriores demostraram a falsidade desses argumentos e revelaram a debilidade dessas forças, tanto do ponto de vista meramente militar como, sobretudo, de uma visão de legitimação política.

Em segundo lugar, essa mesma visão os fez subestimar a força ou a vontade desestabilizadora dos grupos armados partidários do ex-presidente Aristide entrincheirados principalmente nas favelas miseráveis de Porto-Príncipe, especialmente em Cité Soleil. Em um primeiro momento, era como se as forças armadas da Minustha não acreditassem na real capacidade subversiva desses grupos. É certo, como disse o General Heleno, ${ }^{5}$ que depois de um certo tempo, a Minustah e a Polícia Nacional realizaram ações em Bel-Air que levaram a uma relativa pacificação desse forte foco de violência. Similarmente, é preciso destacar a ação das forças

5 O autor se refere ao discurso do general Heleno, primeiro comandante brasileiro MINUSTAH, por ocasião da abertura do Simpósio Internacional Caminhos de Diálogo para a Construção de uma Diplomacia Responsável: a presença do Brasil no Haiti, realizado no UNICEUB, nos dias 27, 28 e 29 de março de 2007. Nota da tradutora. 
de ordem em Cité Soleil que levaria à morte do chamado Dread Wilmé, um dos principais chefes de gangue dessa favela. Apesar dessas ações, reinava a impressão geral que a Minustha não queria agir contra as gangues, como havia feito contra os ex-militares. Chegou-se, inclusive, a culpar as forças de segurança da Minustha de cumplicidade com as gangues criminosas. É evidente que a lenta e muito precavida atuação da Minustha pode ter contribuído, a princípio, para esse tipo de acusação.

Poderíamos dizer que os ex-militares se desfizeram como um castelo de naipes após a morte de seu principal dirigente, o ex comandante Ravix, enquanto que os grupos aristidianos continuavam bem entrincheirados e com alta capacidade de armazenamento de armas e munições. Essa realidade levou o diplomata Edmond Mulet, atual chefe civil da Minustha [sic] e representante oficial do Secretário Geral das Nações Unidas, a dizer que não se sabia de onde esses grupos encontravam tanto dinheiro para renovar e aumentar seu arsenal bélico, deixando supor a existência de «grupos de fora» em tal assunto.

Nessas circunstâncias, sem saber, os latinos serviam facilmente de apoio às políticas populistas com claras orientações antidemocráticas no país. Assim foi com os resultados das eleições presidenciais realizadas em 7 de fevereiro de 2006. Como já se sabe, a diplomacia latino-americana se mobilizou, nisso o Brasil desempenhou um papel importante, buscando subterfúgios para dar a vitória à René Préval, apesar de não ter alcançado $50 \%$ dos votos exigidos pela Constituição. ${ }^{6}$

No entanto, o mais grave é que isso se fez sob pressão das massas populares partidárias de Aristide e de Préval, que ganharam as ruas e exigiram que se desse a vitória a Préval e que não tivesse segundo turno, um método típico de resolução de conflitos pela via da ameaça popular, método que fixa suas raízes históricas em uma larga tradição de caudilhos manipuladores das masas no país aos quais os presidentes Préval e Aristide não podem, de nenhuma maneira, alegar inocência.

É preciso destacar que as forças de ordem da Polícia Nacional e da Minustha desapareceram, como que por encanto, do panorama de Porto Príncipe

\footnotetext{
${ }^{6}$ René Préval alcançou pouco mais de $48 \%$ de votos válidos. Nota da tradutora.
} 
frente às manifestações de rua e, dessa forma, a multidão pôde entrar facilmente no Hotel Montana, onde supostamente estaria o centro de cômputo eleitoral e onde chegaram os ameaçantes partidários de Preval. Nessas circunstâncias de pressões de todos os lados, inclusive do governo interino do presidente Boniface e do primeiro-mnistro Latortue, o Conselho Eleitoral, já com frágil personalidade democrática, cedeu e aceitou a violação da repartição dos votos brancos para dar a vitória a René Préval.

Muito se tem dito que René Préval teria ganhado de qualquer maneira no segundo turno. É muito provável que teria sido assim, mas o comportamento do candidato que chegou em primeiro lugar e da diplomacia latino-americana deixam dúvidas e alimentam as suspeitas daqueles e daquelas que pensam que o ex-presidente Leslie Manigat, que alcançou um longínquo segundo lugar nas eleições presidenciais, poderia vencer se tivesse tido um segundo turno. Daí, talvez, derivam as fortes reações de Manigat. ${ }^{7}$

Ademais, não se pode reduzir a democracia a um assunto de meros resultados eleitorais. Como se sabe, as formas e os procedimentos são de suma importância no sistema democrático. De qualquer maneira, em um país sem tradição democrática, esses fatos não contribuem em nada para cultivar a consciência democrática. Pelo contrário, reforçam as tendências ao caudilhismo e à resolução dos problemas pela força ou coação, à margem dos marcos institucionais. Não se pode deixar de pensar que a atitude dos latino-americanos tenha talvez relação com a tradição de um inconsciente populista, já que o subcontinente está muito familiarizado com esse tipo de regime político e que, não por acaso, o subcontinente latino-americano é considerado como o ápice dos populismos e dos caudilhismos.

À vista do que ocorre contemporaneamente no Haiti, pode-se pensar que os latino-americanos tiveram que passar por uma fase de aprendizagem antes de se inserirem na realidade haitiana. Como disse anteriormente, o Haiti foi para eles um descobrimento que os surpreendeu e, de certa forma, os desorientou.

Leslie Manigat foi presidente do Haiti, no período de 7 de fevereiro a 20 de junho de 1988. Nota da tradutora. 
Hoje em dia, a situação se modificou profundamente. Talvez porque depois de um tempo de indecisão, o governo do presidente Préval decidiu atacar seriamente o fenômeno da insegurança, dos kidnapings ${ }^{8}$ e dos crimes dos grupos armados, e deu cartas brancas à Minustha e à Polícia Nacional para agir de verdade. O fato é que, hoje em dia, tanto o governo como as forças de segurança parecem determinados a pôr fim na onda de violência que estrangula o país. A maioria da população haitiana estava esperando com ansiedade este momento e, de forma inequívoca, a percepção sobre as forças de segurança começa a mudar. É correto que, como disse o General Heleno, houve um acúmulo de experiências, um maior conhecimento do terreno e das formas de agir dos grupos armados, que torna a ação da Minustah mais efetiva hoje, mas também, penso que existe hoje uma maior vontade política tanto por parte do governo haitiano como das forças da ONU e da comunidade internacional como um todo.

A Minustha tem se investido hoje de uma vontade férrea de dar segurança à população, com todo o risco que isso carrega e, nessa missão, as forças brasileiras têm estado na vanguarda. É totalmente falsa a ideia de que as forças brasileiras ou outras da missão das Nações Unidas causam massacres indiscriminados na população. Evidentemente, é impossível assegurar que não tenha havido erros e danos colaterais. Hoje em dia, os êxitos no combate aos principais focos das gangues em Martissant e em Cité Soleil são bons presságios para os tempos futuros. Apesar de ainda estar presente a violência criminosa, Porto Príncipe e o país inteiro começam a respirar um ambiente mais aprazível e de menos tensão. Se essa tendência permanecer, em breve haverá condições bem melhores para empreender as tarefas de reconstrução econômica e social do país.

Por outro lado, os latinos mudaram o discurso: já não colocam a culpa da criminalidade basicamente na pobreza. Simplesmente, tanto o componente civil como o militar da Minustha civil se mostram decididos a combater qualquer força que ameace à segurança da população.

\footnotetext{
8 A tradução possível ao português é "sequestro", mas este termo deve ser mantido em inglês, pois desta forma é elaborado no Haiti. Nota da tradutora.
} 
A orientação sobre a cooperação também está mais clara. Acredito que hoje os países latinos se dão conta que a cooperação sul-sul, tal como se apresenta contemporaneamente, não pode ser de uma apoio leve ao Haiti e que a cooperação com o norte continua sendo a mais segura, apesar de suas grandes limitações.

Já tem havido e continua havendo debates e críticas sobre a efetividade da ajuda do norte ao sul e está claro que seus resultados estão muito longe do esperado. Existem sérios problemas sobre a ajuda e a cooperação que os países do norte e as agências internacionais proporcionam ao Haiti. Fala-se, por exemplo, de sua atomização em uma multiplicidade de pequenas ações, sem a devida articulação. Cada organismo luta em defender sua parcela e inclusive em competir um com o outro. O Estado haitiano, por sua grande fragilidade, é incapaz de articular e de fixar prioridades claras para acionar esses organismos, e as necessidades da população são tão urgentes que se torna difícil recusar o apoio oferecido. Ficaria muito extenso fazer aqui uma análise dos profundos problemas que a cooperação internacional apresenta no Haiti. No entanto, creio que cada um de nossos países latino-americanos conhece e já experimentou as limitações da cooperação internacional, seja no âmbito das instituições multicionais ou organismos bilaterias, como de governo a governo.

\section{Cooperação Brasil- Haiti}

Não tenho conhecimento detalhado de tudo que já se foi discutido entre os governos em matéria de cooperação. Houve várias delegações e personalidades brasileiras que foram ao Haiti discutir as possibilidades de cooperação. Algumas delegações haitianas vieram ao Brasil, como no caso da fabricação do biodiesel. Entretanto, não parece haver ainda um marco de referência bem definido sobre essa colaboração, muito menos uma agenda clara de ações a empreender. Proponho-me aqui a simplesmente pensar em alguns campos possíveis a partir dos quais o Brasil pode dar uma boa contribuição ao Haiti. Em geral, as intenções de cooperação sul-sul abarcam um campo muito amplo. É preciso concentrar os esforços, já que os recursos disponíveis são escassos. 
1. No campo estritamente econômico, acredito que a agricultura constitui o primeiro campo de possível cooperação. Os dois países têm condições climáticas similares e, por isso, apresentam uma história comum de produtos de exportação, tais como café e cacau. Claro que no Haiti a agricultura é basicamente camponesa, ou seja, o agricultor se dedica à exploração de pequenas áreas para uma combinação de propósitos, basicamente para a alimentação familiar e para o mercado. Vale lembrar que o Haiti é um dos países mais rurais do mundo. Existem muito poucos assalariados agrícolas e também poucos grandes proprietários com imensas terras para explorar. No entanto, apesar dessas considerações, existem condições para uma cooperação técnica nesse setor, tanto na produção primária como na transformação agroindustrial na qual o Haiti está praticamente virgem. Dentro dessa mesma área, muito tem se falado sobre a possibilidade de cooperação no campo energético com o etanol e o biodiesel, já que são produzidos com matérias-primas tropicais, as quais o Haiti possui boas condições ecológicas de produção. No entanto, devido à limitação de terras próprias para a produção de alimentos, é evidente que a prioridade deveria ser dada à produção de biodiesel, já que o arbusto medicinal chamado Jatropha é silvestre no Haiti (cresce em condições agroecológicas difíceis) e pode ser utilizado com um duplo propósito: produção de biodiesel e reflorestamento.

2. O segundo campo é, indubitavelmente, o cultural. A verdade é que, se não fosse pela distância, não se entenderia por que o Brasil e o Haiti nunca impulsionaram um audaz programa de cooperação em matéria de música, dança, literatura, pintura, teatro e inclusive cinema. De muitas maneiras, o Brasil tem configurações étnicas, religiosas e culturais semelhantes ao Haiti e existe, nos dois povos, um imaginário muito fértil e criativo, passível de enriquecimento e exploração.

3. Para terminar, é necessário mencionar a cooperação na área de segurança. Esteja ou não a Minustha no Haiti, está claro que a Polícia Nacional Haitiana ou as forças de ordem necessitarão de 
muito mais treinamento e o Brasil, tanto por seu preparo como pela experiência que está acumulando no terreno, deveria ser capaz de continuar apoiando a polícia haitiana.

4. futebol: não se trata propriamente de um campo de cooperação, mas é sem dúvida um forte elemento de aproximação entre os dois povos, já que a população haitiana é movida por uma adoração e um fanatismo sem igual pelo futebol brasileiro.

Provavelmente, o calcanhar de Aquiles da cooperação entre os dois países é a disponibilidade de fundos mínimos para viagens e gastos operacionais. Os dois países estão geograficamente muito afastados e os custos de intercâmbio direto não são baixos. O Brasil é, de qualquer maneira, um país relativamente pobre e não tem provavelmente, como todos os países do subcontinente, muitos recursos destinados a uma cooperação sul-sul ativa. As viagens ao Haiti são caras e levar técnicos e profissionais ao Haiti não é fácil para o Brasil no marco da atual cooperação sul-sul. Pela minha experiência pessoal, este é um dos grandes gargalos da cooperação sul-sul.

Para contornar essa limitação de recursos nasceu o conceito de cooperação triangular, ou seja, uma cooperação que requer a intervenção de um terceiro agente que financie os custos. Meu ponto de vista é que, em alguns casos em que esse método triangular tem de ser promovido, como colocou o embaixador do Canadá Guillermo Rischinsky, ${ }^{9}$ tem dado resultados positivos, mas não se pode contar com ele como um mecanismo geral de cooperação.

Penso que, a despeito dessas limitações, um esforço mais determinante faz-se necessário para que os países latinos ofereçam um apoio econômico e social real ao Haiti. Penso também que uma cooperação e um apoio real ao Haiti implica ao Brasil e, em geral, ao subcontinente latino-americano e caribenho, a tomada de decisões que superem e revolucionem os estreitos marcos da cooperação sul-sul

9 O autor se refere ao discurso do ex-embaixador canadense no Brasil, quando da abertura do Simpósio Internacional Caminhos de Diálogo para a Construção de uma Diplomacia Responsável: a presença do Brasil no Haiti, realizado no UNICEUB, nos dias 27, 28 e 29 de março de 2007. Nota da tradutora. 
atual. Com modéstia, digo que o Haiti merece esse esforço tanto pelo simbolismo de seu grande feito heróico de independência, como pela ativa solidariedade que ofereceu à causa libertária de muitos povos da região.

O Haiti representa agora um verdadeiro teste para o subcontinente na demonstração de que, na era da globalização econômica e do império desenfreado do individualismo, é possível ainda cultivar os valores da solidariedade,de que as velhas utopias humanistas não morreram no subcontinente e que podem perfeitamente se conjugar e harmonizar maior eficiência, maior bem-estar material com valores espirituais que engrandecem o ser humano. E nisso, a Universidade tem um papel importante a desempenhar. Esta própria Conferência no UNICEUB e o próprio convite que me fizeram para estar com vocês hoje respondem claramente a essa aspiração de trascendência espiritual do ser humano a qual aspira a universidade.

Agradeço-lhes a atenção. Quarta-feira, 28 de março de 2007. 